This accepted author manuscript is copyrighted and published by Elsevier. It is posted here by agreement between Elsevier and MTA. The definitive version of the text was subsequently published in Carbon, 109, 2016, DOI: 10.1016/j.carbon.2016.07.063 Available under license CC-BY-NC-ND.

\title{
Gas barrier properties of oxyfluorinated graphene filled polytetrafluoroethylene nanocomposites
}

LJ van Rooyen*a,b, H Bissett ${ }^{\mathrm{a}}$, MC Khoathane ${ }^{\mathrm{b}}$, J Karger-Kocsis ${ }^{\mathrm{b}, \mathrm{c}}$

a Applied Chemistry, South African Nuclear Energy Corporation SOC Limited, P.O Box 582, Pretoria, 0001, South Africa

b Tshwane University of Technology (TUT), Faculty of Engineering and the Built Environment, P.O. Box 680, Pretoria, 0001, South Africa

c MTA-BME Research Group for Composite Science and Technology, Muegyetem rkp. 3, H-1111 Budapest, Hungary

Abstract:

The helium gas permeability of polytetrafluoroethylene (PTFE)/graphene nanocomposites was studied as a function of surface treatment and filler loading of the graphene nanoplatelets. Graphene was incorporated into PTFE up to 7 vol\% via a solvent-assisted blending method and the composites sintered. The surface modification of the graphene occurred by oxyfluorination in perfluoroheptane solvent. The surface characteristics of the graphene nanoplatelets were assessed by X-ray photoelectron, Raman and infrared spectroscopy techniques and discussed. The incorporation of the oxyfluorinated and commercial grade graphene into the PTFE reduced the helium gas permeability by $96 \%$ at 4 vol $\%$ and by $88 \%$ at 7 vol $\%$ nanofiller contents, respectively. Oxyfluorination of graphene resulted in better dispersion of the graphene nanoplatelets compared to the unmodified ones. This was evidenced by scanning electron microscopy and X-ray tomographic inspection. The helium gas permeability of the PTFE nanocomposites was modelled by applying certain tortuosity models. The Bharadwaj model proved to be the most appropriate to describe the measured barrier properties. The modified Bharadwaj model suggested that the actual 
aspect ratio of the oxyfluorinated graphene was higher than that of the unmodified graphene nanoplatelets in the PTFE matrix. Accordingly, oxyfluorination proved to be a useful method to support the graphene intercalation with PTFE molecules.

Key words: polytetrafluoroethylene (PTFE), graphene, helium permeation, tortuosity modelling, aspect ratio, surface modification, surface fluorination

\section{Introduction}

Fluoropolymers are used extensively in the oil and gas industries due to their exceptional properties like chemical inertness and thermal stability over a wide range of temperatures. Fluoroelastomers are generally applied as seals or gasket material for high gas pressure applications. However, these fluoroelastomeric seals are susceptible to rapid gas decompression (RGD) [1]. This phenomenon is caused by the diffusion of a gas into the polymer whilst under pressure and when the pressure is released the pressure differential in the polymer causes mechanical or explosive damage of the polymer matrix $[2,3]$. Polytetrafluoroethylene (PTFE) is often used as a substitute when an elastomer is unsuitable for a specific pressure or chemical application due to its lacking mechanical strength and chemical inertness. However, PTFE is known to be vulnerable to gas permeation more than the elastomeric seals due to the processing methods used to fabricate finished articles.

PTFE exhibits a high molecular weight and crystallinity and therefore exhibits a high melt viscosity close or above the melting temperature [4]. Hence, PTFE is normally processed using sintering methods applied in powder metallurgy and not with conventional polymer processing methods like extrusion and injection moulding. Unlike melt processing, this sintering process produces micro-voids in the PTFE polymer matrix which leads to an increase in gas permeation [5]. Gases like helium and hydrogen 
permeate easily through PTFE which make it difficult to leak test PTFE gasket seals [6]. Hence, the gas permeation properties of PTFE and its copolymers is not as comprehensively studied compared to its well-known thermal and mechanical properties [7]. Gas permeation studies utilising helium as a tracer gas has been effective to measure the gas barrier properties of polymer and composite membranes [8-11]. Furthermore, there exists a good correlation between helium permeation and the permeation of some other gases like hydrogen, oxygen, and carbon dioxide through polymer membranes [12]. Therefore, helium may serve as a good modelling gas to describe the gas barrier properties of polymer seals used in various industries.

The incorporation of platelet shaped fillers to reduce the helium gas permeation in polymers has received significant attention in the past few years [9,13-16]. Graphene nanoplatelets show enormous potential to prepare polymer nanocomposites with enhanced gas barrier properties due to its high aspect ratio[17-20] and impermeability to gases like helium [21-24]. If dispersed homogeneously in a polymer matrix, then the graphene nanoplatelets form a tortuous path that restricts the migration of gaseous molecules through the polymer matrix $[25,26]$. However, the dispersion of nanofillers like graphene into PTFE is difficult [27]. Researchers have recently shown how to improve the dispersion of graphene in PTFE through electrostatic self-assembly [27] and by using perfluorinated solvents [28]. Also, good chemical compatibility between the filler and the polymer matrix normally reduces the gas permeability even further [29]. However, the compatibility of graphene with most polymer matrices is known to be poor $[17,30]$. The chemical inertness of the PTFE polymer matrix further inhibits interaction between the polymer chains and the filler. 
Surface modification of graphene has shown to be an effective method to improve the polymer/filler compatibility which in turn also improves the gas barrier properties of graphene filled polymer composites [30-32]. This strategy of surface modification of graphene has also been followed by others to improve the tribological performance of PTFE nanocomposites [33-35]. The hypothesized explanation for the favoured formation of a tribofilm of PTFE on the steel counter surface was due to the complex formation via participation of carbonyl/carboxylic groups which evolved from tribochemical processes in PTFE $[33,35]$. This has also been observed with graphene filled PTFE composites which indicated that the carboxylic groups on the PTFE surface have improved interaction with the graphene nanoplatelets, which was associated with a prominent decrease of the coefficient of friction [36]. The surface fluorination or oxyfluorination of graphene might be a suitable alternative method to improve the compatibility with the PTFE polymer matrix. Oxyfluorination of graphene oxide (G0) has shown to improve the dispersion of GO in polyvinyl alcohol (PVA) [37]. However, the preparation of polymer nanocomposites containing oxyfluorinated graphene (OFGR) appears to be limited.

Therefore, this study was aimed at preparing PFTE/graphene nanocomposites whilst modifying the surface characteristics of the graphene nanoplatelets and confirming how this modification affected the helium gas permeability of the related nanocomposites. For the surface modification of graphene, a facile method via oxyfluorination in a perfluorinated solvent was selected. A further aim of this study was to apply different tortuosity-based permeation models to describe the experimental results in order to obtain further insights into the dispersion and orientation of the graphene platelets. 


\section{Experimental}

\subsection{Materials}

\subsubsection{PTFE moulding powder}

The PTFE moulding powder (TFM 1700, 3M Dyneon, Germany) used in this study is a free flowing grade with a specific density of $2.16 \mathrm{~g} \cdot \mathrm{cm}^{-3}$ and an average particle size of $25 \mu \mathrm{m}$. This grade of PTFE is a modified PTFE which contains perfluoro (alkyl vinyl ether) groups through copolymerisation. The amount of the perfluoro (alkyl vinyl ether) groups in this PTFE copolymer is less than $2 \mathrm{wt} \%$ which was expected to improve the interaction between the graphene and the PTFE surface due to the presence of oxygen groups.

\subsubsection{Graphene nano-fillers}

The graphene nanoplatelets (M-25, further denoted to as XGnP) used in this study were sourced from XG Sciences (USA) which exhibited a specific density of $2.2{\mathrm{~g} . \mathrm{cm}^{-3}}^{-3}$ an average particle size of $25 \mu \mathrm{m}$, and an oxygen content of less than $1 \%$ according to the supplied specification sheet. The oxyfluorinated graphene nanoplatelets (OFGR) were prepared in a liquid phase reaction with fluorine gas (Pelchem, South Africa) where the as-received graphene nanoplatelets (XGnP) were dispersed in perfluoroheptane (PFH) (Pelchem, South Africa).

\subsubsection{Surface modification of graphene nanoplatelets through oxyfluorination}

To modify the surface of the as received graphene nanoplatelets a direct oxyfluorination approach was used. To prepare a batch, the as received graphene nanoplatelets $(2 \mathrm{~g})$ were dispersed in $100 \mathrm{~cm}^{3}$ of PFH using sonication for $5 \mathrm{~min}$. After sonication, the dispersion of graphene nanoplatelets/PFH was transferred to a $120 \mathrm{~cm}^{3}$ reactor 
(contains a water jacket for cooling) where the contents were stirred with a cross magnetic bar and heated to $40{ }^{\circ} \mathrm{C}$ with a heating unit (Julabo $\mathrm{GmbH}$, Germany). Atmospheric air was kept in the reactor at $98 \mathrm{kPa}$ whilst fluorine gas was dosed in with a mass flow meter (Bronkhorst EL Flow metal sealed, Netherlands) at a rate of 0.2 g.h $^{-1}$ for $2 \mathrm{~h}$. The reaction was then left to continue for another $24 \mathrm{~h}$ at $40{ }^{\circ} \mathrm{C}$ which resulted in reactor pressure increasing to about $160 \mathrm{kPa}$. After the reaction was completed, the reactor was purged with nitrogen as to remove any residual fluorine gas. The contents were drained into $100 \mathrm{~cm}^{3}$ of demineralised water as to wash the graphene and functionalise the surface even further. The mixture was filtered and dried at $70{ }^{\circ} \mathrm{C}$ for $72 \mathrm{~h}$ in an oven. The oxyfluorination of the graphene was roughly based on the methods described by Bierschenk et al [38] and Han et al [37].

\subsubsection{Characterisation of graphene nanoplatelets and surface modified graphene} nanoplatelets

Characterisation of the as-received and the oxyfluorinated graphene was performed using spectroscopic techniques.

X-ray Photoelectron Spectroscopy (XPS) analysis was performed using a Thermo Scientific (Waltham, MA, USA) ESCALAB 250Xi X-ray Photoelectron Spectrometer fitted with an $\mathrm{Al} \mathrm{K \alpha}$ radiation source at $300 \mathrm{~W}$. Wide (Pass energy $=100 \mathrm{eV}$ ) and narrow (Pass energy $=20 \mathrm{eV}$ ) scans were performed with a $900 \mu \mathrm{m}$ beam diameter. The deconvolution of the narrow scanned peaks were performed with Origin 9.0 (Originlab Corporation, Northampton, MA, USA) and fitted to a Gaussian function.

A Renishaw (United Kingdom) InVia Reflex Raman spectrometer system equipped with RenCam CCD detector cooled at $-70{ }^{\circ} \mathrm{C}$ was used for Raman spectra acquisition. The Raman excitation radiation wavelength of $488 \mathrm{~nm}$ from an Argon-Ion laser (Model: 
Stellar-REN Multiline) was used. The power setting of $1 \mathrm{~mW}$ at the sample was used throughout the study. A LEICA DM 2700 Microscope fitted with 100X magnification objective lens was used on the microscope.

Fourier Transform Infrared Spectroscopy of the graphene nanoplatelets surface was performed on a Perkin Elmer Spectrum 65 spectrometer. The as-received graphene and the oxyfluorinated graphene (2 mg) were mixed with $\mathrm{KBr}$ powder (100 mg). The graphene/KBr powder was dried for $72 \mathrm{~h}$ before being pressed into $\emptyset 10 \mathrm{~mm}$ discs. The scan range was performed from $600-4000 \mathrm{~cm}^{-1}$ taking 128 scans per analysis.

\subsection{PTFE/graphene composite preparation}

The guidelines specified by van Rooyen et al [28] were used with regards to preparing the PTFE /graphene blends and how to fabricate the disc samples.

\subsubsection{Preparation of PTFE/nano-filler powders}

The as-received (XGnP) and oxyfluorinated graphene (OFGR) were incorporated into the PTFE at $0.25 ; 0.75 ; 1 ; 2 ; 4 ;$ and 7 vol\% graphene loadings, respectively, through solvent assisted blending. The graphene nanoplatelets were dispersed in $200 \mathrm{~cm}^{3}$ of PFH for $1 \mathrm{~h}$ at $30^{\circ} \mathrm{C}$ using an ultrasonic bath (Scientech 702, $100 \mathrm{~W}$, South Africa). Afterwards, the graphene/PFH dispersion was combined and blended with $30 \mathrm{~g}$ of PTFE for $3 \mathrm{~h}$ using a magnetic stirrer and follower (MR Hei-Tec, Heidolph, Germany). The homogenous PTFE/graphene powder blend was filtered as to remove the PFH and dried for $24 \mathrm{~h}$ at $70^{\circ} \mathrm{C}$ under vacuum to remove any residual $\mathrm{PFH}$ in the powder blend. The collected agglomerate of PTFE/graphene was de-agglomerated into finer particles in a blender for $10 \mathrm{~s}$. 


\subsubsection{PTFE/graphene composite disc fabrication}

The composite permeation samples were prepared as disc samples with a diameter of $50 \mathrm{~mm}$ and a thickness of approximately $3 \mathrm{~mm}$. To produce a preform disc sample with these dimensions, an amount of $12 \mathrm{~g}$ of the prepared PTFE/graphene powder was weighed and transferred to a mould (EQ-DIE-50D, MTI Corporation, USA) with an inside diameter of $50 \mathrm{~mm}$. The blended powder was compressed at a preform pressure of 12.8 $\mathrm{MPa}$ using a hydraulic press (Hytec, South Africa) at $25^{\circ} \mathrm{C}$. The preform pressure was applied and held for 5 min and steadily released. The preform disc samples were dried for $3 \mathrm{~h}$ at $100{ }^{\circ} \mathrm{C}$ as to remove any residual moisture. The preform disc samples were sintered using a programmable sintering oven (Carbolite HT, United Kingdom) which sequentially increased the temperature to $380^{\circ} \mathrm{C}$, held the temperature $\left(380^{\circ} \mathrm{C}\right)$ for a required period, and cooled the samples slowly to room temperature. The temperature profile for the sintering of the disc samples is described in more detail by van Rooyen et al [28]. Unfilled TFM 1700 disc samples were also prepared as reference samples using the same fabrication methods.

\subsection{Characterisation of composite}

\subsubsection{Helium permeation}

The helium gas permeation was measured using a permeation cell which was connected to a helium leak detector (VS Pro 2, Varian Inc, USA). The gas permeation set-up has been described elsewhere [16] with the exception that the clamping disc of the permeation cell was slightly modified to accommodate disc samples with a diameter of $50 \mathrm{~mm}$. The permeant gas used was high purity (99.999\%) helium gas (Helium 5.0, African Oxygen Limited, South Africa) which was flowed into the top chamber of the permeation cell at a rate of $50 \mathrm{ml} \cdot \mathrm{min}^{-1}$ whilst the bottom section was connected to the 
helium leak detector and evacuated to a pressure of $1.2 \times 10^{-2} \mathrm{~Pa}$. The tests were performed in a temperature controlled laboratory at $24^{\circ} \mathrm{C}$ and 3 disc sample repeats were done for each unmodified graphene and oxyfluorinated graphene concentration. A metal disc was also analysed as to verify the sealing ability of the permeation cell and to eliminate the concern that major permeation occurred through the Viton O-rings. The helium leak rate was checked and verified periodically using the internal calibrated leak $\left(1.4 \times 10^{-8} \mathrm{~Pa} \cdot \mathrm{m}^{3} \cdot \mathrm{s}^{-1}\right)$ which is factory fitted.

\subsubsection{Composite morphology}

The morphology of the composite discs were investigated using a SUPRATM 40VP (Carl Zeiss SMT AG, Jena, Germany) ultra-high resolution Field Emission Scanning Electron Microscope (FESEM) operating at a $5 \mathrm{kV}$ acceleration voltage, a working distance of less than $10 \mathrm{~mm}$ and a secondary electron detector. Cross-sectional regions were prepared with cryo-fracturing and the surfaces were sputter coated with gold for $80 \mathrm{~s}$ to improve the sample conductivity.

X-ray tomography scans of the composite discs were performed on a Nikon (Metris XT H 225L, Japan) microfocus X-ray scanner with the power settings set at $100 \mathrm{kV}$ for the tube voltage and $100 \mu \mathrm{A}$ current for the tungsten target. The scan duration was for approximately 60 min to measure 2000 projections using a scan rate of 0.5 frames per second. The lowest detectable pixel resolution for the composite disc was ca $27.6 \mu \mathrm{m}$. Smaller sections ( $\varnothing 6 \mathrm{~mm} \times 3 \mathrm{~mm}$ ) were sampled from the main disc for more accurate scans and to improve the resolution (ca $4.5 \mu \mathrm{m}$ ). 


\section{Results and discussion}

\subsection{Characterisation of graphene and oxyfluorinated graphene surface}

The XPS analysis of the reference graphene nanoplatelets and the oxyfluorinated graphene was performed to understand the bonding states of the functional groups on the filler surface. From the wide scans of the fillers it was shown that the unmodified graphene showed mainly carbon and oxygen elements, whereas the oxyfluorinated graphene showed an additional fluorine element peak (Figure 1). The elemental data is compiled in Table 1 and the fluorine and oxygen content increased when compared to unmodified graphene. Furthermore, the carbon content reduced from 95.3 at $\%$ to 91.6 at $\%$ which indicated that functionalization did occur.
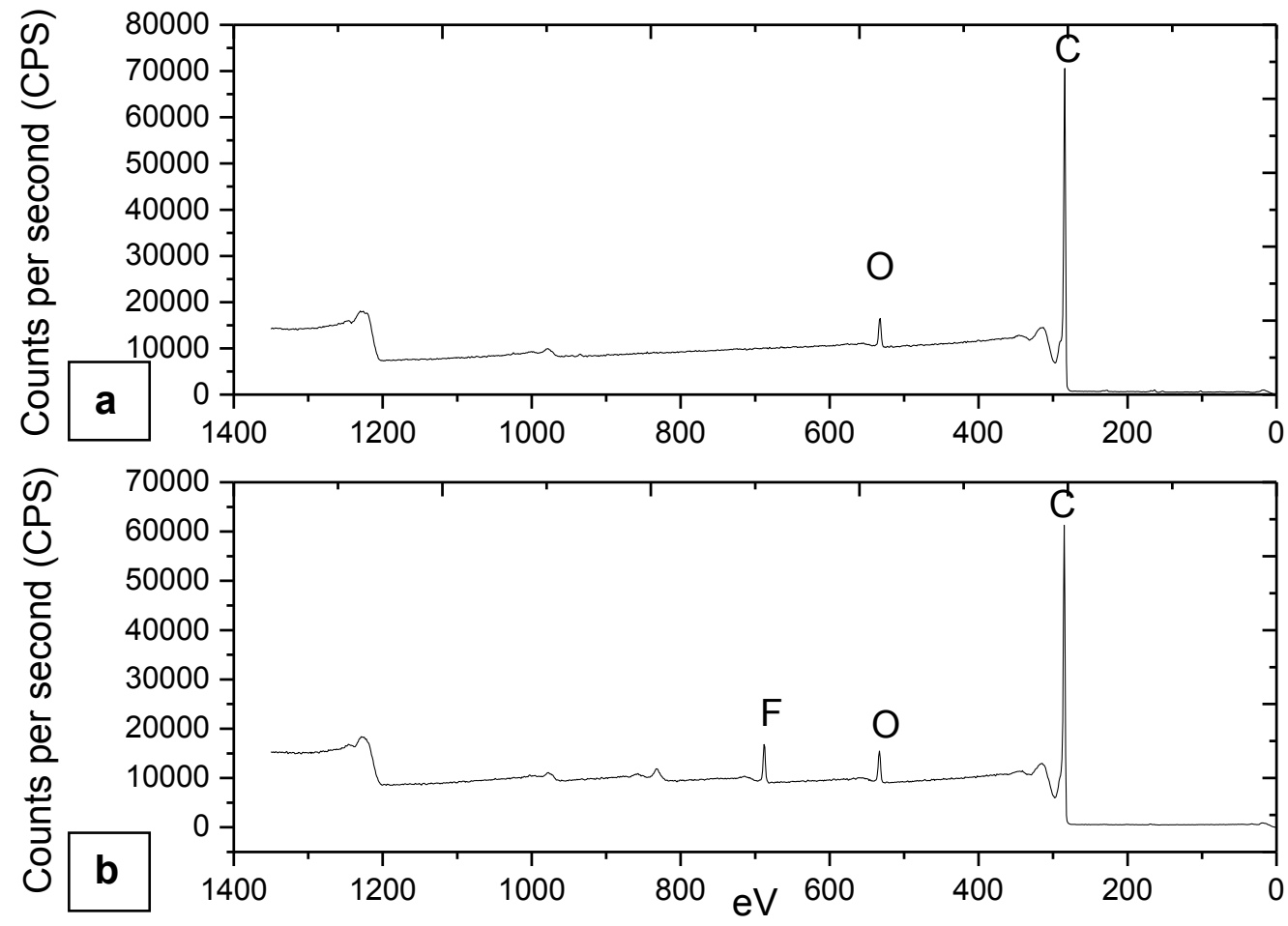

Figure 1: Wide scan XPS spectra of (a) unmodified (XGnP) and (b) oxyfluorinated (OFGR) graphene 
Table 1: XPS elemental analysis of the as received graphene (XGnP M25) and oxyfluorinated (OFGR)

\begin{tabular}{ccccc}
\hline Sample & Element & Atomic \% & Binding energy (eV) & Probable bonds \\
\hline \multirow{3}{*}{ XGnP } & $\mathrm{C}$ & 95.3 & 283.9 & $\mathrm{C}-\mathrm{C}$ \\
& $\mathrm{O}$ & 4.1 & 532.0 & $0-(\mathrm{C}, \mathrm{H})$ \\
& $\mathrm{S}$ & 0.4 & - & - \\
\hline \multirow{3}{*}{ OFGR } & $\mathrm{Si}$ & 0.2 & - & - \\
& $\mathrm{C}$ & 91.6 & 284.6 & $\mathrm{C}-\mathrm{C}$ \\
& $\mathrm{O}$ & 4.7 & 532.8 & $0-(\mathrm{C}, \mathrm{H})$ \\
\end{tabular}

Narrow scans of the C1, 01 and F1 were also performed and deconvolution of the peaks was done using Gaussian function fits (Figure 2 \& Figure 3). It must be noted that due to the complicated nature of CF bonds, the assigning of the binding energy and deconvolution analysis were done as closely as possible to literature values that are relevant to oxyfluorinated or fluorinated graphene and carbon nanotubes [39-47]. The unmodified graphene produced a definitive $\mathrm{sp}^{2}$ carbon (C-C) peak at $283.9 \mathrm{eV}$ and after deconvolution two minor additional peaks were also shown at $284.8 \mathrm{eV}$ and $285.6 \mathrm{eV}$ which may be assigned to $\mathrm{sp}^{3} \mathrm{C}$ attached to oxygen groups (C-C-O) and $\mathrm{C}-\mathrm{OH}$ groups (Figure 2) [39]. The 01 scan of the unmodified graphene showed a predominant a peak of carbonyl groups $(\mathrm{C}=\mathrm{O})$, with some alcohol $(\mathrm{C}-\mathrm{OH})$ and carboxylic acid $(\mathrm{O}=\mathrm{C}-\mathrm{OH})$ groups (Figure 2). 

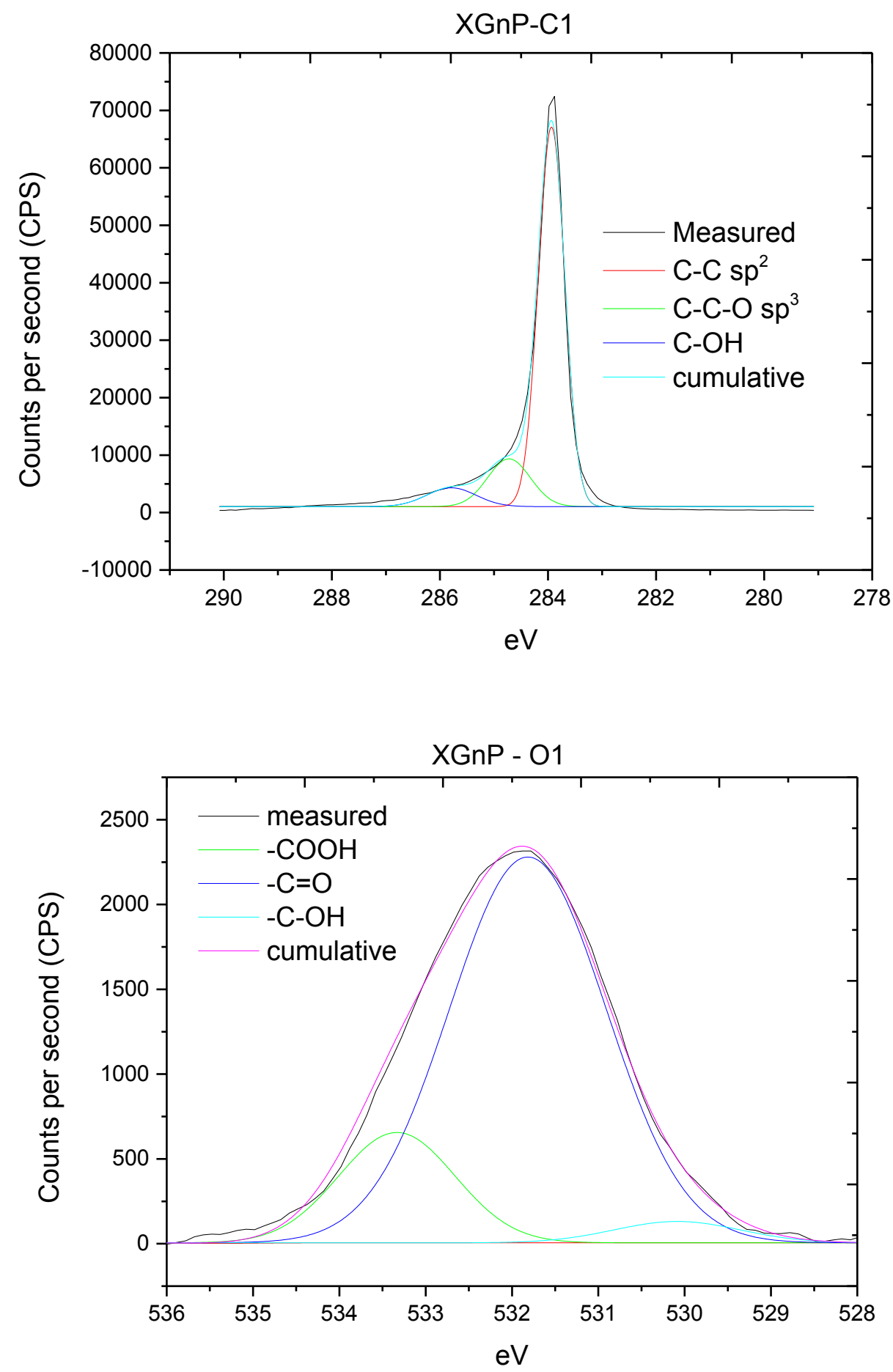

Figure 2: Narrow XPS scans of unmodified graphene C1 and 01

The deconvolution of the oxyfluorinated graphene produced additional peaks when compared to the unmodified graphene at $285.5,286.5,287.6$, and $288.6 \mathrm{eV}$ which may 
be assigned to $\mathrm{sp}^{3}$ carbon bonds with fluorine attached to it $(\mathrm{C}-\mathrm{C}-\mathrm{F}), \mathrm{C}=\mathrm{O}$, semi-ionic $\mathrm{CF}$, and covalently bonded CF in low concentrations (Figure 3). The C1 peak profile of the oxyfluorinated graphene did not show a distinct shoulder of peaks as what would be expected with graphene oxide or fluorographene with higher concentrations of oxygen and fluorine groups on the surface. Due to the low concentration of fluorine and oxygen on the surface the main carbon peak resembled more a pristine carbon peak of graphene and carbon nanotubes that are partially fluorinated $[40,42,43,46]$. This was mainly due to the low $\mathrm{C} / \mathrm{F}$ ratio [48]. The F1 scans confirmed the formation of semiionic and covalent CF bonds at 687.1 and $688.7 \mathrm{eV}$ on the surface of the graphene after oxy-fluorination (Figure 3). This also confirms that the $\mathrm{sp}^{3}$ carbons are the main regions being affected by the fluorination. The 01 scans showed that the oxyfluorinated graphene had an additional peak at $534.9 \mathrm{eV}$ that might be attributed to the formation of complex oxyfluoride (OCF) groups (Figure 3) [39]. The washing step with demineralised water appeared to remove a lot of the fluorine groups from the surface as the formation of the peak at $286.5 \mathrm{eV}$ indicated the formation of $\mathrm{C}=0$ bonds. A possible mechanism may be the formation of acid fluoride groups on the surface during the reaction step and after being washed with demineralised water forming carboxylic acid groups. 

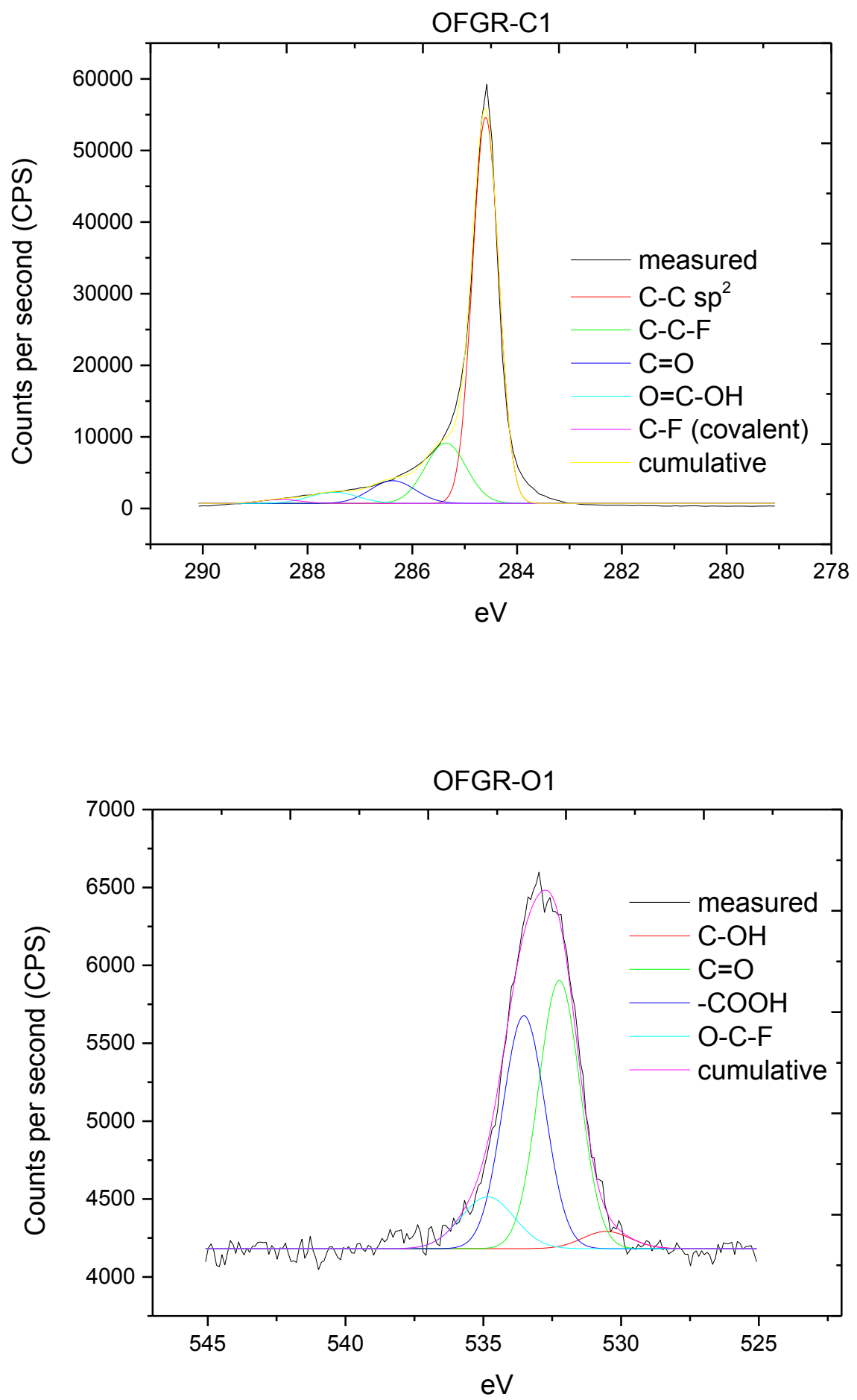


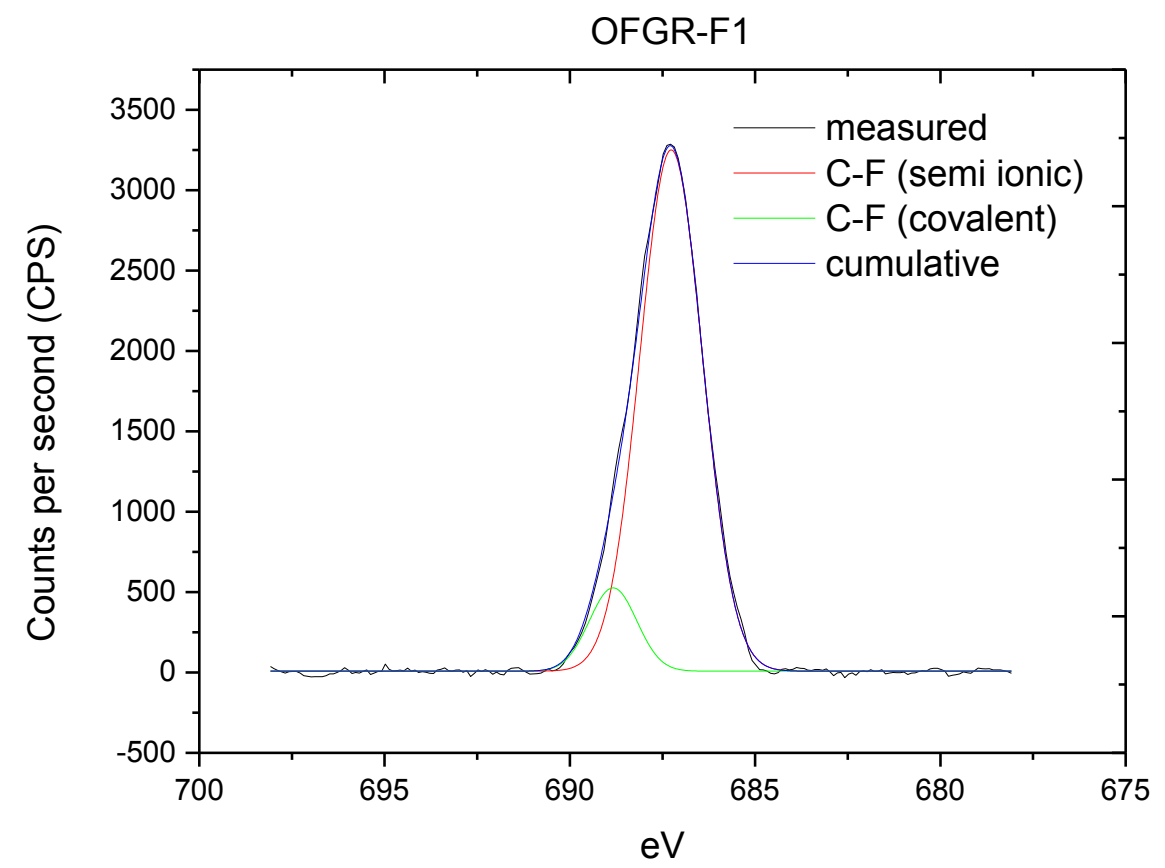

Figure 3: Narrow XPS scans of oxyfluorinated graphene C1; 01; and F1

The FT-IR analysis showed clear peaks at 3400, 2926, 2852, 1736, 1654, 1610, 1455, 1384 , and $1125 \mathrm{~cm}^{-1}$ which were inherent of both the unmodified and oxyfluorinated graphene (Figure 4). The formation of a peak at around $1239 \mathrm{~cm}^{-1}$ may be attributed to CF bonds which was absent in the spectra of the unmodified graphene $[37,47,49,50]$. 


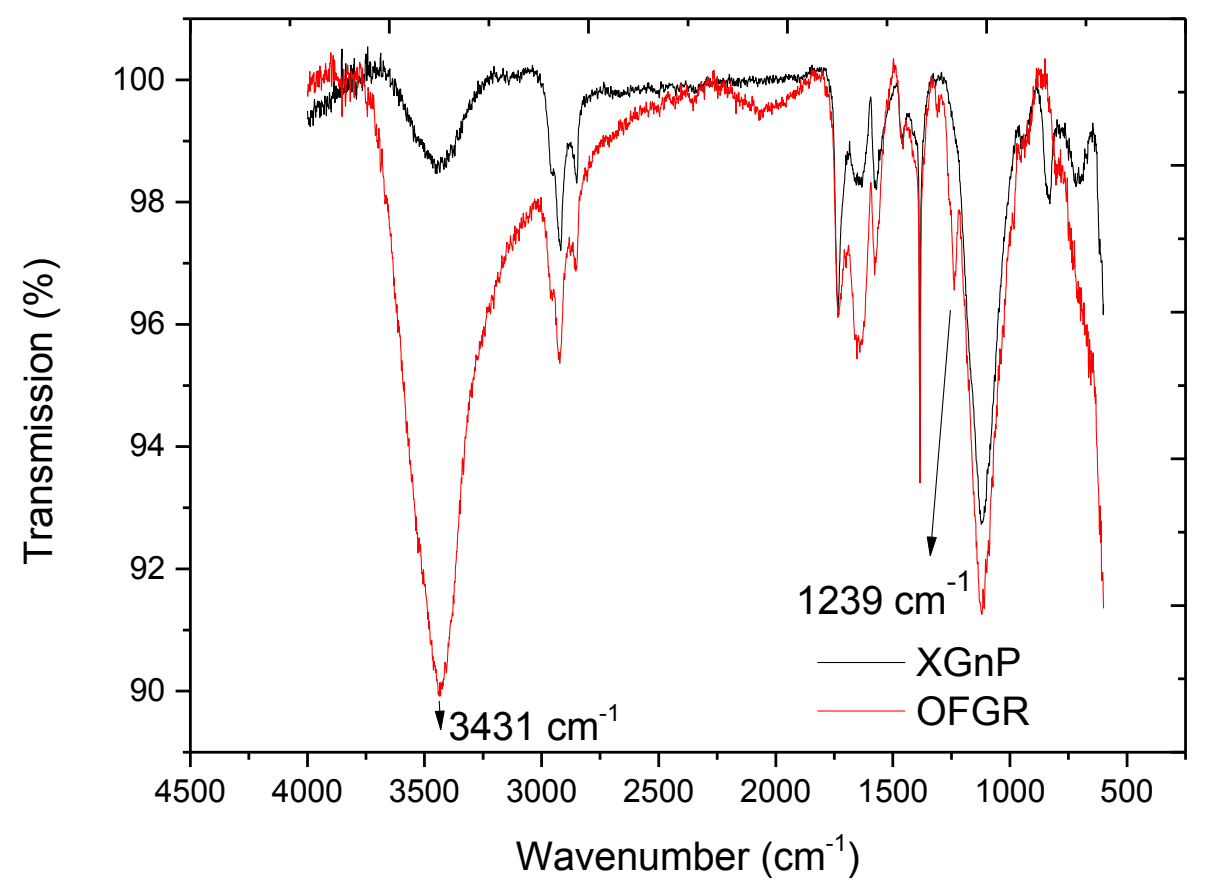

Figure 4: Infrared spectra of the unmodified (XGnP) graphene and the oxyfluorinated graphene nanoplatelets

The Raman spectra of the unmodified graphene produced the typical peaks at around 1366, 1582, and $2741 \mathrm{~cm}^{-1}$ (Figure 5). These peaks are known as the D, G, and 2D bands. The D and the G bands of the oxyfluorinated graphene shifted to lower energy wavenumbers ( $D=1354 \mathrm{~cm}^{-1}$ and $\left.\mathrm{G}=1574 \mathrm{~cm}^{-1}\right)$ which has been observed by other researchers as fluorine content on and in-between the graphene layers increase [51,52]. An indication of disorder in graphene platelets is usually described by the intensity ratio between the $\mathrm{D}$ and $\mathrm{G}$ bands $(I D / I G)[45]$. The $I D / I G$ ratio of the graphene after oxyfluorination slightly reduced from 0.26 to 0.18 when compared to the $I D / I G$ ratio of the unmodified graphene. This indicated that the $\mathrm{sp}^{2} \mathrm{C}-\mathrm{C}$ structure of the graphene was altered after oxyfluorination. This may also indicate the separation of the outside layers 
of the graphene which exposed more pristine layers of graphene present in-between the other layers [53].

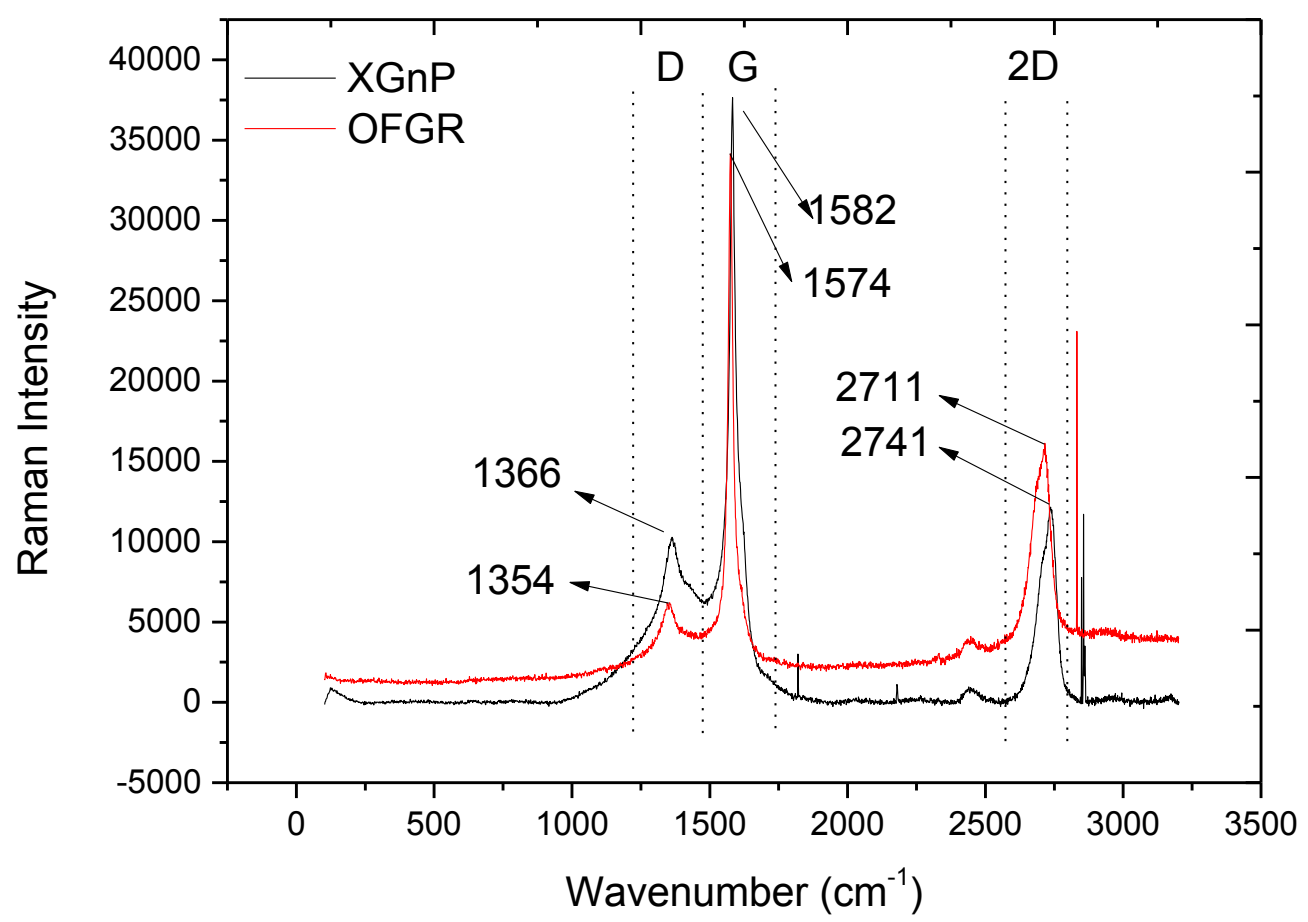

Figure 5: Raman spectra of the unmodified (XGnP) graphene and the oxyfluorinated graphene nanoplatelets

\subsection{Helium permeability}

\subsubsection{Helium permeation measurements as to determine the diffusion coefficient} and steady state gas flux

Helium leak detectors are being used more frequently as a quick method to measure the gas permeability of polymers or composite materials [12]. The helium leak rate $U^{*}$ ) was measured in Pa.m ${ }^{3} \cdot \mathrm{s}^{-1}$ and logged using the Varian Leak Test Data Wizard software (USA). The helium gas flux $\left(J\right.$, mol. $\left.\mathrm{m}^{-2} . \mathrm{s}^{-1}\right)$ was calculated from;

$$
J=\frac{J^{*}}{A R T}
$$


where, $A$ is the surface area $\left(0.0013 \mathrm{~m}^{2}\right), R$ the gas constant $\left(8.315 \mathrm{~J} . \mathrm{K}^{-1} \cdot \mathrm{mol}^{-1}\right)$ and $T$ the temperature $(297 \mathrm{~K})$.

From the helium gas permeation experiments (Supplementary section; Figure S1) it was evident that the incorporation of graphene and the oxyfluorinated graphene nanoplatelets reduced the permeation with increasing concentration of the respective graphene filler material (Figure 6). The unmodified graphene initially did not show a significant reduction but only as the concentration increased. The functionalization of the graphene nanoplatelets significantly reduced the helium gas permeation at lower concentrations when compared to the unmodified graphene. The higher concentrations at 4 and 7 vol\% were the most effective at reducing the helium permeation.

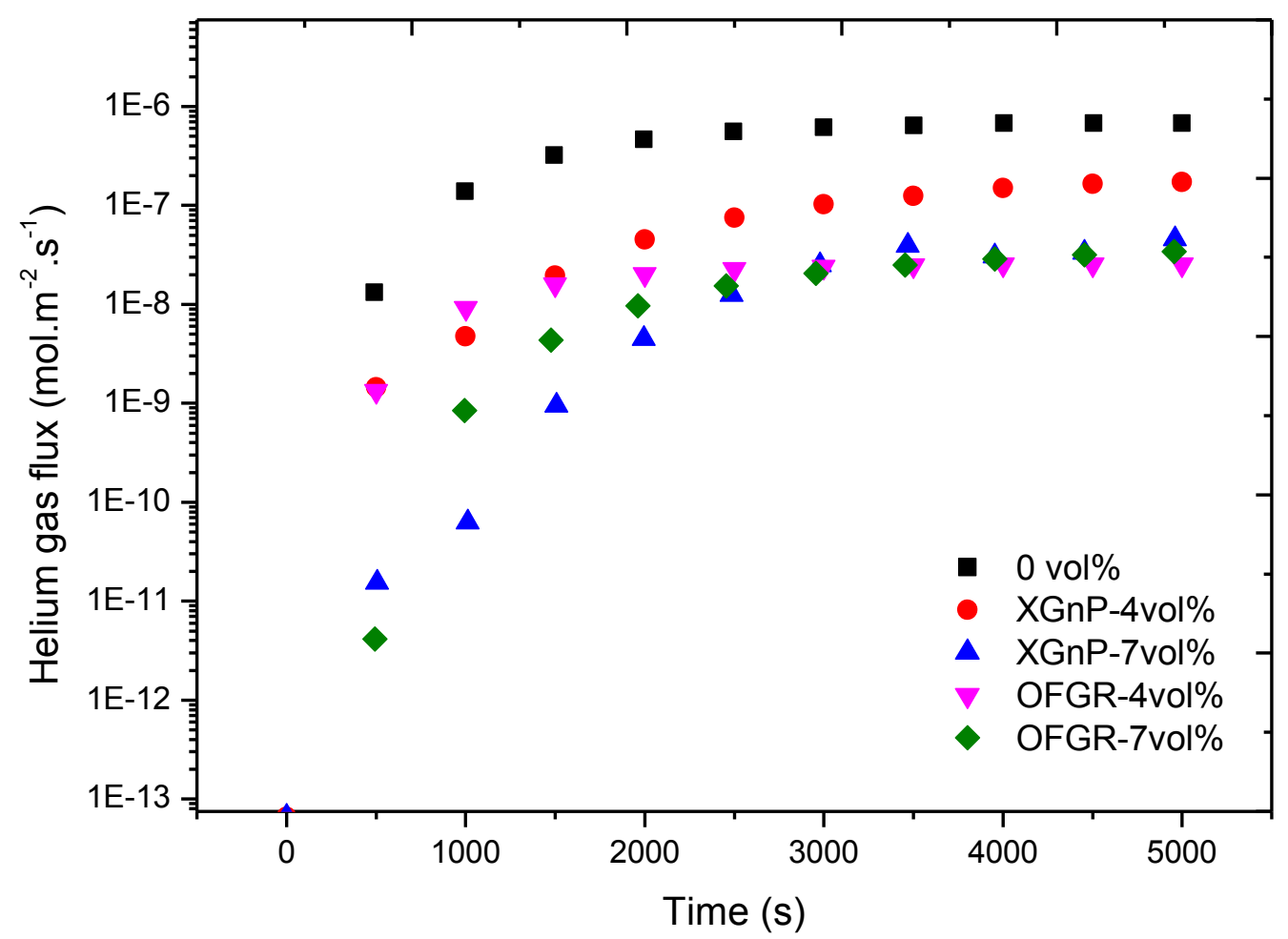

Figure 6: Helium gas permeation flux measurements of the unmodified (XGnP) and the oxyfluorinated (OFGR) graphene filled PTFE composite discs 
The helium gas diffusion $(D)$ coefficients and steady state flux $\left(J_{0}\right)$ of the PTFE nanocomposites were determined from the following one-dimensional variation of Fick's law of diffusion with appropriate boundary conditions $[8,9,54]$ :

$$
J=J_{0} \sqrt{\frac{4 d^{2}}{\pi D t}} \sum_{x=0}^{\infty} \exp \left[-\frac{d^{2}}{4 D t}(2 x+1)^{2}\right]
$$

where $J$ is the calculated helium gas flux and $J_{0}$ is the steady-state helium gas flux $\left(\mathrm{mol} \cdot \mathrm{m}^{-2} \cdot \mathrm{s}^{-1}\right), d$ is the sample disc thickness $(\mathrm{m}), t$ the time (s), and $D$ is the diffusion coefficient $\left(\mathrm{m}^{2} \cdot \mathrm{s}^{-1}\right)$.

A simplified form of Equation 2 can be applied in the earlier stages of gas diffusion, as an approximation:

$$
J \cong J_{0} \sqrt{\frac{4 d^{2}}{\pi D t}} \exp \left(-\frac{d^{2}}{4 D t}\right)
$$

The diffusion coefficient $(D)$ and the steady-state helium flux $\left(J_{0}\right)$ were determined by plotting the linear form (Equation 4$) ; \ln (\mathrm{J} \sqrt{\mathrm{t}})$ against $1 / \mathrm{t}$ and the results were fitted to a linear trend line [16].

$$
\ln (J \sqrt{t}) \cong-\left(\frac{d^{2}}{4 D}\right) \frac{1}{t}+\ln J_{0} \sqrt{\frac{4 d}{\pi D}}
$$

The linear fit of Eq 4 showed minor statistical deviation with the gas flux permeation data which allowed for accurate approximation of the diffusion co-efficient $(D)$ and steady-state flux ( 0 ) (Table 2). The steady state flux for the oxyfluorinated graphene showed the best reduction when compared to the unmodified graphene. However, the diffusion coefficient values of the oxyfluorinated and the unmodified graphene 
exhibited a similar trend of reduction when compared. Nonetheless, the diffusion coefficient was still reduced with increasing concentration of either filler. The diffusion coefficient of the unmodified graphene exhibited the highest reduction of $75 \%$ at 7 vol\% relative to the reference PTFE samples $\left(9.27 \times 10^{-10} . \mathrm{m}^{2} . \mathrm{s}^{-1}\right.$ to $\left.2.29 \times 10^{-10} . \mathrm{m}^{2} . \mathrm{s}^{-1}\right)$ which might be questionable due to the large standard deviation. However, this result may be seen as an outlier. The reduction of the diffusion coefficient and the steady state flux was mainly influenced by the fillers forming a complex structure which limited the migration of the helium gas molecules through the polymer matrix. Furthermore, the fabrication method showed to be effective in reducing the helium permeation.

Table 2: Calculated steady state flux $\left(J_{0}\right)$ and diffusion coefficient $(D)$ values from the permeation flux data according to the one-dimensional Fickian equation

\begin{tabular}{|c|c|c|c|c|c|c|}
\hline $\begin{array}{l}\text { Loading } \\
\text { (wt\%) }\end{array}$ & Filler & 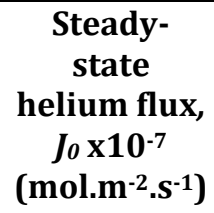 & $\begin{array}{l}\text { Standard } \\
\text { deviation }\end{array}$ & $\begin{array}{c}\text { Diffusion } \\
\text { coefficient, } \\
D \times 10^{-10} \\
\left(\mathrm{~m}^{2} . \mathrm{s}^{-1}\right)\end{array}$ & $\begin{array}{r}\text { Standard } \\
\text { deviation }\end{array}$ & $\begin{array}{c}\text { Linear } \\
\text { fit } \\
\left(R^{2}\right)\end{array}$ \\
\hline 0 & None & 7.15 & 0.1 & 9.27 & 0.1 & 0.996 \\
\hline 0.25 & Graphene & 4.75 & 0.12 & 7.77 & 0.26 & 0.993 \\
\hline 0.75 & Graphene & 4.72 & 0.15 & 7.21 & 0.1 & 0.994 \\
\hline 1 & Graphene & 4.33 & 0.23 & 6.37 & 0.2 & 0.986 \\
\hline 2 & Graphene & 2.44 & 0.15 & 7.88 & 0.1 & 0.992 \\
\hline 4 & Graphene & 1.77 & 0.21 & 4.48 & 0.28 & 0.980 \\
\hline 7 & Graphene & 0.96 & 0.4 & 2.29 & 2 & 0.93 \\
\hline 0.25 & $\begin{array}{l}\text { Oxyfluorinated } \\
\text { graphene }\end{array}$ & 2.33 & 0.11 & 7.41 & 0.13 & 0.994 \\
\hline 0.75 & $\begin{array}{l}\text { Oxyfluorinated } \\
\text { graphene }\end{array}$ & 2.28 & 0.1 & 7.45 & 0.1 & 0.996 \\
\hline 1 & $\begin{array}{l}\text { Oxyfluorinated } \\
\text { graphene }\end{array}$ & 1.90 & 0.14 & 7.16 & 0.12 & 0.993 \\
\hline 2 & $\begin{array}{l}\text { Oxyfluorinated } \\
\text { graphene }\end{array}$ & 1.62 & 0.1 & 5.60 & 0.1 & 0.997 \\
\hline 4 & $\begin{array}{l}\text { Oxyfluorinated } \\
\text { graphene }\end{array}$ & 0.26 & 0.02 & 4.35 & 0.17 & 0.977 \\
\hline
\end{tabular}


Scanning Electron Microscope images of the oxyfluorinated and unmodified graphene filled PTFE composites confirmed the intricate morphology that was formed (Figure S2). The oxyfluorinated and unmodified graphene showed to be well dispersed with random orientation throughout the polymer matrices (Figure S2). Furthermore, the nanoplatelets showed good adhesion to the polymer surface which explained the improvement in the barrier properties (Figure S3). The use of micro-focus x-ray tomography enabled the scanning of the entire sample to further explain the morphology of the oxyfluorinated and unmodified graphene/PTFE composite discs. The oxyfluorinated and unmodified graphene/PTFE composite discs were three-dimensionally reconstructed using the VGStudio Max 2.2 (Volume Graphics GmbH, Germany) computer software package (Figure S4). By attenuating only the denser graphene particles, it was revealed that the oxyfluorinated and unmodified graphene were uniformly dispersed throughout the composite discs with random orientation of the nanoplatelets (Figure S4). This confirmed the structures observed with the SEM images. Moreover, some kind of percolation threshold can be observed at 7 vol\% of the graphene nanoplatelets. The use of PFH solvent demonstrated to be the best method to disperse the oxyfluorinated graphene with the PTFE powder which in turn created a tortuous maze structure [28].

\subsubsection{Helium permeability coefficient and tortuous path modelling}

By normalizing the steady-state helium gas flux $\left(U o\right.$, mol.m- $\left.{ }^{-2} . \mathrm{s}^{-1}\right)$ with the permeation sample thickness $(d, \mathrm{~m})$, the helium permeability coefficient $\left(P, \mathrm{~mol} \cdot \mathrm{m}^{-1} \cdot \mathrm{s}^{-1} \cdot \mathrm{Pa}^{-1}\right)$ was determined from the following equation: 


$$
P=\frac{J_{0} d}{\Delta p}
$$

where $\Delta p$ is the differential gas pressure (Pa) and the atmospheric test pressure was measured to be $86 \mathrm{kPa}$.

The helium permeability coefficient $(P)$ was reduced significantly with the oxyfluorinated graphene displaying the best results (Figure 7). This may be attributed to the better interaction of the oxyfluorinated graphene with the polymer matrix. In comparing the unmodified and oxyfluorinated graphene fillers, the largest reduction achieved by the oxyfluorinated graphene was $96 \%$ at a filler concentration of 4 vol\% whereas the largest reduction of the permeability for the unmodified graphene was $88 \%$ at a higher loading of 7 vol\%. Both fillers created a tortuous structure which limited the mobility of the gas molecules through the matrix.

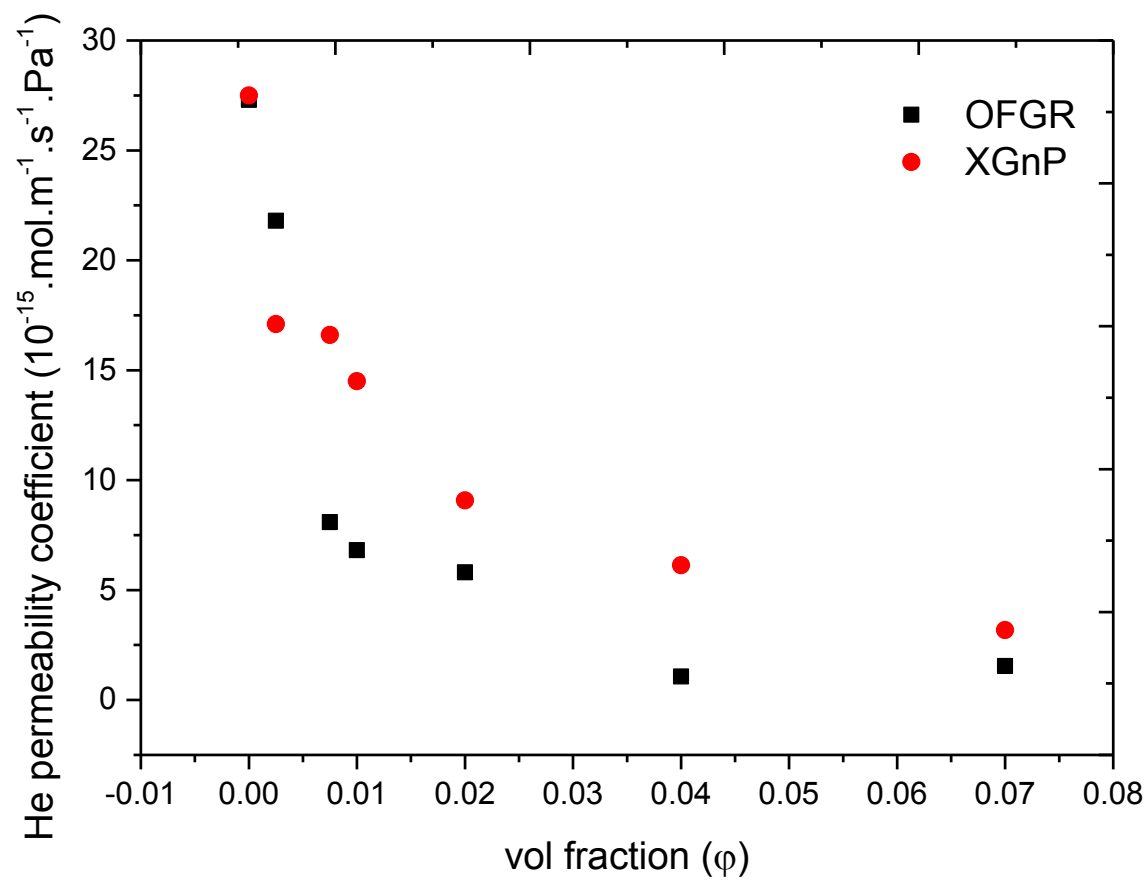

Figure 7: Helium gas permeability coefficients of the unmodified and oxyfluorinated graphene filled PTFE composites 
Based on the tortuous path theory, the influence that this tortuous structure has on the permeability can generally be described with the following equation;

$$
R p=\frac{P_{c}}{P_{0}}=\frac{1-\phi}{\tau}
$$

where $P_{c}$ is the permeability coefficient of the composite polymer, $P_{0}$ is the permeability coefficient of the pure polymer, $\phi$ is the nanoplatelet volume fraction, and $\tau$ is the tortuosity factor.

Various tortuosity models have been developed to describe how nanofillers influence the gas permeability of polymer composites. However, the filler geometry needs to be considered when applying these models to describe the reduction in permeability. The models considered in this study were for platelet or disc shaped fillers (Table 3). From the fitting of the models it showed that the aspect ratio for the oxyfluorinated graphene was significantly larger when compared to the unmodified graphene (Table 4). The surface modification allowed for better dispersion of the filler in the polymer matrix. The largest aspect ratio was predicted by the Bharadwaj model with an S"-value of 0 (cf. Table 3) which describes a random orientation of the graphene filler samples. The aspect ratio of ca 650 for the unmodified graphene is similar to what has been observed and confirmed in other studies [15]. The Bharadwaj model in general is better suited to describe the morphology of graphene filled composites due to the orientation of the particles which are not considered by the other models. The fibre orientation analysis module in VGstudio max 2.2 was used to analyse the oxyfluorinated platelet orientation in a planar direction which was positioned perpendicularly to the permeation direction in the oxyfluorinated and unmodified graphene composite matrices. The histograms generated from the orientation analysis indicated that orientation of the graphene 
nanoplatelets varied between $30^{\circ}$ and $56^{\circ}$ (Figure S5). This confirmed the S"-value (cf. Table 3) of 0 which corresponded to a random distribution of the graphene platelets.

Table 3: Tortuosity models

\begin{tabular}{|c|c|c|c|c|}
\hline Model & Filler geometry & Filler dispersion & $\begin{array}{c}\text { Aspect } \\
\text { ratio }\end{array}$ & Tortuosity factor $(\tau)$ \\
\hline Nielsen [55] & Ribbon & Regular array & $\mathrm{w} / \mathrm{t}$ & $1+\frac{\alpha \phi}{2}$ \\
\hline $\begin{array}{c}\text { Lape/Cussler- } \\
\text { regular array[26] }\end{array}$ & Ribbon & Regular array & $\mathrm{w} / \mathrm{t}$ & $1+\frac{\alpha^{2} \phi^{2}}{4}$ \\
\hline $\begin{array}{l}\text { Lape/Cussler- } \\
\text { random array[26] }\end{array}$ & Ribbon & Random array & $\mathrm{w} / \mathrm{t}$ & $\left(1+\frac{\alpha \phi}{3}\right)^{2}$ \\
\hline *Bharadwaj[56] & Ribbon & $\begin{array}{c}\text { Random array and } \\
\text { orientation }\end{array}$ & $\mathrm{w} / \mathrm{t}$ & $1+\left[\frac{\alpha \phi\left(2 S^{\prime \prime}+1\right)}{6}\right]$ \\
\hline $\begin{array}{l}\text { **Fredrickson- } \\
\text { Bicerano[57] }\end{array}$ & Disc & Random array & $\mathrm{d} / \mathrm{t}$ & $\begin{array}{r}4\left[\left(1+x+0.1245 x^{2}\right) /(2\right. \\
+x)]^{2}\end{array}$ \\
\hline Gusev-Lusti[58] & Disc & Random array & $\mathrm{d} / \mathrm{t}$ & $\exp \left[\left(\frac{\alpha \phi /}{3.47}\right)^{0.71}\right]$ \\
\hline
\end{tabular}

*Factor $S^{\prime \prime}$ is incorporated with $\theta$ being the angle between the obstructing filler and penetrant flow.

$$
S^{\prime \prime}=\frac{3 \cos ^{2} \theta-1}{2}
$$

**Factor $x$ is incorporated. $x=\pi \alpha \phi /\left[2 \ln \left(\frac{\alpha}{2}\right)\right]$ 
Table 4: Predicted aspect ratios from tortuosity models

\begin{tabular}{ccccc}
\hline Model & \multicolumn{2}{c}{ Unmodified graphene } & \multicolumn{2}{c}{ Oxyfluorinated graphene } \\
& $\underline{\text { Predicted aspect ratio }}$ & $\underline{R^{2}}$ & $\underline{\text { Predicted aspect ratio }}$ & $\underline{R^{2}}$ \\
Nielsen & 220 & 0.934 & 456 & 0.954 \\
Lape/Cussler-regular array & 190 & 0.707 & 380 & 0.967 \\
Lape/Cussler-random array & 125 & 0.928 & 255 & 0.963 \\
Bharadwaj (S"=0) & 650 & 0.935 & 1467 & 0.951 \\
Fredrickson-Bicerano & 350 & 0.930 & 872 & 0.956 \\
Gusev-Lusti & 195 & 0.941 & 425 & 0.951 \\
\hline
\end{tabular}


From the SEM and X-ray tomography images the average diameter of the oxyfluorinated graphene was approximately $20 \mu \mathrm{m}$ which is close to the average platelet diameter stated on the specification sheet of XG Sciences. To confirm this observation, the 2dimensional images from the X-ray tomography were analysed with Image (RSB, National Institute of Mental Health, USA). The particle size distribution showed to range between 15 and $21 \mu \mathrm{m}$ from 408 particle counts with the average diameter being at $18 \mu \mathrm{m}$ (Figure S6). The thickness calculated from the effective aspect ratio (Table 4) varied from $10.22-13.65 \mathrm{~nm}$ for the oxyfluorinated graphene and 23.08-30.77 $\mathrm{nm}$ for the unmodified graphene. The thickness of the oxyfluorinated graphene platelets correspond with other data that has been observed previously [15]. This confirmed the possible separation of the outer graphene layers after the washing step which would increase the effective aspect ratio of graphene platelets as observed with the Raman analysis (Figure 5). The surface modification showed to improve the dispersion of the graphene platelets whereas the unmodified graphene still showed some intercalated regions in the PTFE matrix. This stacking of the of the graphene nanoplatelet layers to form an intercalated network may be described by incorporating a stacking parameter $\langle N\rangle$ into the Bharadwaj model as follow;

$$
\tau=1+\left[\frac{\alpha \phi\left(2 S^{\prime \prime}+1\right)}{6} \cdot \frac{1}{\langle N\rangle}\right]
$$

where, $\tau$ is the tortuosity factor; $\alpha$ is the aspect ratio; $\phi$ is the nanoplatelet volume fraction; and $S^{\prime \prime}$ is the orientation correction factor.

The actual thickness of the unmodified graphene nanoplatelets has been observed with Transmission Electron Microscopy (TEM) by other researchers to be less than $10 \mathrm{~nm}$ which is similar to what is claimed by the manufacturers (XG sciences) to be between 
6-8 $\mathrm{nm}$ [59]. Using this actual measured thickness gives a larger aspect ratio of ca 3000 when using the measured average diameter of $18 \mu \mathrm{m}$ (Figure S6 b). Using the $\langle N\rangle$ parameter showed that the platelet stacking is less for the oxyfluorinated graphene at 2 than the unmodified graphene nanoplatelets at 5 (Figure 8). This clearly indicated the separation of the graphene platelets after oxyfluorination. It has been observed with unmodified graphene that smaller platelets tend to adhere to the larger platelets which increase the formation of stacking in a composite matrix [59]. The amount of layers corresponded to the thickness determined from the effective aspect ratio described by the unaltered Bharadwaj model. The modified Bharadwaj model showed to be a more accurate equation to describe the morphology of the PTFE/graphene composites with regards to how stacking of the graphene platelets influence the aspect ratio. This alteration of the Bharadwaj model has also been recommended by other researchers to better describe platelet shaped filled polymer composites [60].

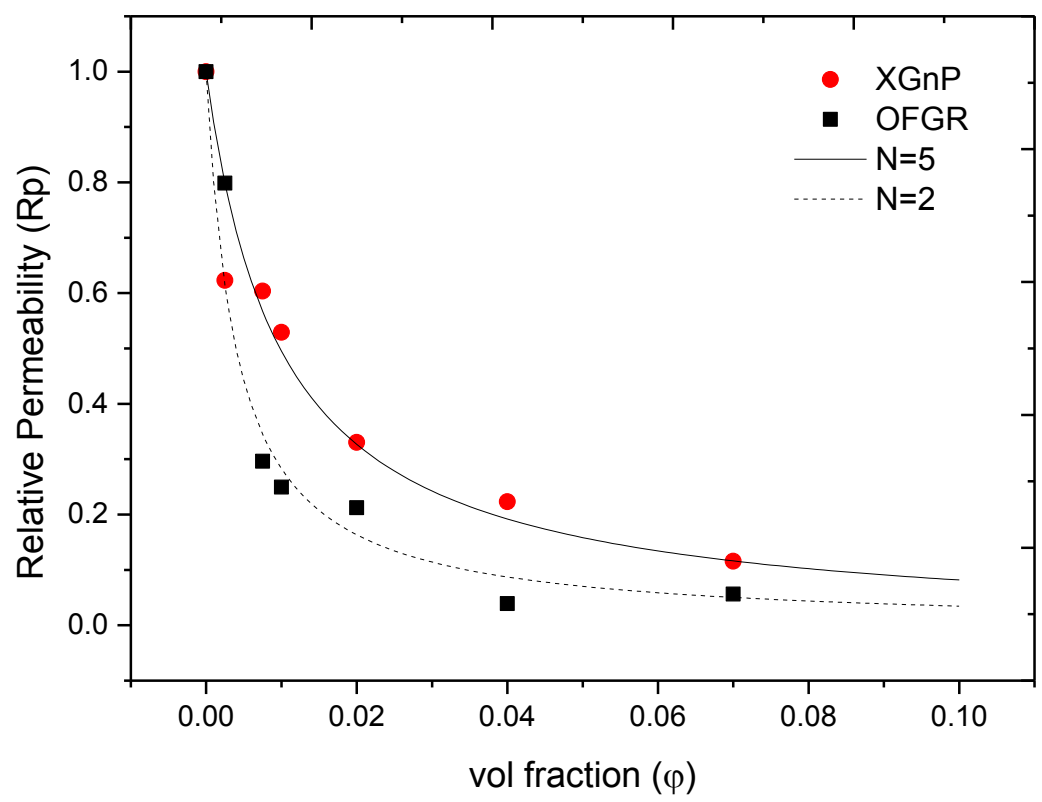


Figure 8: Modified Bharadwaj model showing the degree of stacking of the graphene nanoplatelets for the oxyfluorinated graphene and the unmodified graphene PTFE composites

\section{Conclusion}

With this study, surface modified and unmodified graphene were incorporated into PTFE and the helium gas barrier properties were measured. The surface modification by oxyfluorination was successfully performed in a perfluoroheptane solvent, and it was confirmed through characterisation techniques like XPS, FTIR, and Raman spectroscopy. The incorporation of these fillers reduced the helium gas permeability by an order of magnitude with the oxyfluorinated graphene showing the significant improvement. The oxyfluorinated exhibited a $96 \%$ reduction at a loading of 4 vol\% oxyfluorinated graphene and $88 \%$ at a loading of 7 vol\% of unmodified graphene. The "barrier" percolation threshold showed to be at loadings at about 7 vol\% for both fillers where they were involved in highly interconnected networks. Investigation of the composite morphology with microscopic and tomographic techniques revealed that the oxyfluorinated graphene was randomly dispersed and orientated in the composite matrix. Modelling of the relative permeability with tortuosity models indicated that the aspect ratio of the graphene nanoplatelets increased after oxyfluorination of the platelet surface. This indicated that the washing step probably degrade the outer layers of the functionalised graphene and exposed the inner layers of the graphene platelets as was indicated by the decrease in the $I D / I G$ ratio observed with the Raman analysis. The Bharadwaj model $\left(S^{\prime \prime}=0\right)$ showed the best correlation with the permeability results due to the confirmed orientation of the oxyfluorinated graphene platelets in the PTFE matrix. Altering of the Bharadwaj model by incorporating a stacking parameter further showed to be a better description of the PTFE/graphene composites. Possible further improvement of the orientation of the oxyfluorinated graphene platelets in the polymer 
matrix may also reduce the gas permeability even further with the improved aspect ratio of the oxyfluorinated graphene.

\section{Acknowledgements}

The authors would like to thank Necsa and the Fluorochemical Expansion Initiative (funded by the Department of Science and Technology (DST)) for financial support for this project and for providing the polymer and filler material. Mr JW Hoffman and LC Bam from the Radiation Science department for performing the microfocus x-ray tomography and the DST/NRF for funding the microfocus x-ray system. Mr D van der Westhuizen from the Organic Fluorine Chemistry (OFC) section for making available the equipment for the oxyfluorination of the graphene particles and his assistance with the experiments. Dr LD Kock (Delta-F) for the Raman analysis of the graphene platelets. Mrs L Mostert from the National Metrology Institute of South Africa (NMISA) for the XPS analysis performed on the graphene samples. Dr AD Pienaar (Delta-F) for the help with the deconvolution of the XPS data. Mr E Padenko from the Institute for Composite Materials, University of Kaiserslautern (Germany) for the SEM images on the composite discs. Mr W Ludwick from Pelchem for the supply of perfluoroheptane.

\section{References}

[1] Z. Major, R.W. Lang, Characterization of the fracture behavior of NBR and FKM grade elastomers for oilfield applications, Eng. Fail. Anal. 17 (2010) 701-711. doi:10.1016/j.engfailanal.2009.08.004.

[2] J. Jaravel, S. Castagnet, J.-C. Grandidier, G. Benoît, On key parameters influencing cavitation damage upon fast decompression in a hydrogen saturated elastomer, Polym. Test. 30 (2011) 811-818. doi:10.1016/j.polymertesting.2011.08.003.

[3] O. Lorge, B.J. Briscoe, P. Dang, Gas induced damage in poly(vinylidene fluoride) exposed to decompression, Polymer. 40 (1999) 2981-2991. doi:10.1016/S00323861(98)00527-8. 
[4] Z.H. Zhao, J.N. Chen, Preparation of single-polytetrafluoroethylene composites by the processes of compression molding and free sintering, Compos. Part B Eng. 42 (2011) 1306-1310. doi:10.1016/j.compositesb.2011.01.005.

[5] P.J. Abbott, J.H. Chow, Anomalous Behavior of Teflon-based Helium Permeation Leak, NCSL Int. Meas. 2 (2007) 24-32.

[6] J.V. Dobson, M.J. Taylor, The permeability of gases through PTFE and other membranes at $25^{\circ} \mathrm{C}$, Electrochimica Acta. 31 (1986) 231-233. doi:10.1016/00134686(86)87113-4.

[7] L. Monson, S.I. Moon, C.W. Extrand, Gas permeation resistance of various grades of perfluoroalkoxy-polytetrafluoroethylene copolymers, J. Appl. Polym. Sci. 111 (2009) 141-147. doi:10.1002/app.28858.

[8] T. Yokozeki, T. Aoki, T. Ishikawa, The effect of matrix cracks on gas permeability through CFRP laminates, Adv. Compos. Mater. 13 (2004) 227-236. doi:10.1163/1568551042580136.

[9] T. Ogasawara, Y. Ishida, T. Ishikawa, T. Aoki, T. Ogura, Helium gas permeability of montmorillonite/epoxy nanocomposites, Compos. Part Appl. Sci. Manuf. 37 (2006) 2236-2240. doi:10.1016/j.compositesa.2006.02.015.

[10] T. Yokozeki, T. Ogasawara, T. Aoki, T. Ishikawa, Experimental evaluation of gas permeability through damaged composite laminates for cryogenic tank, Compos. Sci. Technol. 69 (2009) 1334-1340. doi:10.1016/j.compscitech.2008.05.019.

[11] B.R. Murray, S.B. Leen, C.O.A. Semprimoschnig, C.M.Ó. Brádaigh, Helium permeability of polymer materials as liners for composite overwrapped pressure vessels, J. Appl. Polym. Sci. 133 (2016) n/a-n/a. doi:10.1002/app.43675.

[12] K. Muller, J. Botos, M. Bastian, P. Heidemeyer, T. Hochrein, Faster Results, Kunststoffe Int. (2011) 62-67.

[13] P.K. Maji, N.K. Das, A.K. Bhowmick, Preparation and properties of polyurethane nanocomposites of novel architecture as advanced barrier materials, Polymer. 51 (2010) 1100-1110. doi:10.1016/j.polymer.2009.12.040.

[14] S. Takahashi, H.A. Goldberg, C.A. Feeney, D.P. Karim, M. Farrell, K. O'Leary, D.R. Paul, Gas barrier properties of butyl rubber/vermiculite nanocomposite coatings, Polymer. 47 (2006) 3083-3093. doi:10.1016/j.polymer.2006.02.077.

[15] L.J. van Rooyen, J. Karger-Kocsis, L. David Kock, Improving the helium gas barrier properties of epoxy coatings through the incorporation of graphene nanoplatelets and the influence of preparation techniques, J. Appl. Polym. Sci. 132 (2015) n/an/a. doi:10.1002/app.42584.

[16] L.J. van Rooyen, J. Karger-Kocsis, O.C. Vorster, L.D. Kock, Helium gas permeability reduction of epoxy composite coatings by incorporation of glass flakes, J. Membr. Sci. 430 (2013) 203-210. doi:10.1016/j.memsci.2012.11.083.

[17] Y. Cui, S.I. Kundalwal, S. Kumar, Gas barrier performance of graphene/polymer nanocomposites, Carbon. 98 (2016) 313-333. doi:10.1016/j.carbon.2015.11.018.

[18] H. Kim, A.A. Abdala, C.W. Macosko, Graphene/Polymer Nanocomposites, Macromolecules. 43 (2010) 6515-6530. doi:10.1021/ma100572e.

[19] J.R. Potts, D.R. Dreyer, C.W. Bielawski, R.S. Ruoff, Graphene-based polymer nanocomposites, Polymer. 52 (2011) 5-25. doi:10.1016/j.polymer.2010.11.042.

[20] V. Singh, D. Joung, L. Zhai, S. Das, S.I. Khondaker, S. Seal, Graphene based materials: Past, present and future, Prog. Mater. Sci. 56 (2011) 1178-1271. doi:10.1016/j.pmatsci.2011.03.003.

[21] V. Berry, Impermeability of graphene and its applications, Carbon. 62 (2013) 1-10. doi:10.1016/j.carbon.2013.05.052. 
[22] J.S. Bunch, S.S. Verbridge, J.S. Alden, A.M. van der Zande, J.M. Parpia, H.G. Craighead, P.L. McEuen, Impermeable atomic membranes from graphene sheets, Nano Lett. 8 (2008) 2458-2462.

[23] R.R. Nair, H.A. Wu, P.N. Jayaram, I.V. Grigorieva, A.K. Geim, Unimpeded permeation of water through helium-leak-tight graphene-based membranes, Science. 335 (2012) 442-444.

[24] B.M. Yoo, H.J. Shin, H.W. Yoon, H.B. Park, Graphene and graphene oxide and their uses in barrier polymers, J. Appl. Polym. Sci. 131 (2014) 39628-39650. doi:10.1002/app.39628.

[25] J.P. DeRocher, B.T. Gettelfinger, J. Wang, E.E. Nuxoll, E.L. Cussler, Barrier membranes with different sizes of aligned flakes, J. Membr. Sci. 254 (2005) 21-30. doi:10.1016/j.memsci.2004.12.025.

[26] N.K. Lape, E.E. Nuxoll, E.L. Cussler, Polydisperse flakes in barrier films, J. Membr. Sci. 236 (2004) 29-37. doi:10.1016/j.memsci.2003.12.026.

[27] H. Jiang, L. Chen, S. Chai, X. Yao, F. Chen, Q. Fu, Facile fabrication of poly (tetrafluoroethylene)/graphene nanocomposite via electrostatic self-assembly approach, Compos. Sci. Technol. 103 (2014) 28-35. doi:10.1016/j.compscitech.2014.08.007.

[28] L.J. van Rooyen, H. Bissett, M.C. Khoathane, J. Karger-Kocsis, Preparation of PTFE/graphene nanocomposites by compression moulding and free sintering: A guideline, J. Appl. Polym. Sci. 133 (2016) n/a-n/a. doi:10.1002/app.43369.

[29] D. Pierleoni, Z.Y. Xia, M. Christian, S. Ligi, M. Minelli, V. Morandi, F. Doghieri, V. Palermo, Graphene-based coatings on polymer films for gas barrier applications, Carbon. 96 (2016) 503-512. doi:10.1016/j.carbon.2015.09.090.

[30] T. Kuila, S. Bose, A.K. Mishra, P. Khanra, N.H. Kim, J.H. Lee, Effect of functionalized graphene on the physical properties of linear low density polyethylene nanocomposites, Polym. Test. 31 (2012) 31-38.

[31] P. Bandyopadhyay, W.B. Park, R.K. Layek, M.E. Uddin, N.H. Kim, H.-G. Kim, J.H. Lee, Hexylamine functionalized reduced graphene oxide/polyurethane nanocompositecoated nylon for enhanced hydrogen gas barrier film, J. Membr. Sci. 500 (2016) 106-114. doi:10.1016/j.memsci.2015.11.029.

[32] R.K. Layek, A.K. Das, M.J. Park, N.H. Kim, J.H. Lee, Enhancement of physical, mechanical, and gas barrier properties in noncovalently functionalized graphene oxide/poly(vinylidene fluoride) composites, Carbon. 81 (2015) 329-338. doi:10.1016/j.carbon.2014.09.065.

[33] K.L. Harris, A.A. Pitenis, W.G. Sawyer, B.A. Krick, G.S. Blackman, D.J. Kasprzak, C.P. Junk, PTFE Tribology and the Role of Mechanochemistry in the Development of Protective Surface Films, Macromolecules. 48 (2015) 3739-3745. doi:10.1021/acs.macromol.5b00452.

[34] H.S. Khare, A.C. Moore, D.R. Haidar, L. Gong, J. Ye, J.F. Rabolt, D.L. Burris, Interrelated Effects of Temperature and Environment on Wear and Tribochemistry of an Ultralow Wear PTFE Composite, J. Phys. Chem. C. 119 (2015) 16518-16527. doi:10.1021/acs.jpcc.5b00947.

[35] T. Onodera, K. Kawasaki, T. Nakakawaji, Y. Higuchi, N. Ozawa, K. Kurihara, M. Kubo, Effect of Tribochemical Reaction on Transfer-Film Formation by Poly(tetrafluoroethylene), J. Phys. Chem. C. 118 (2014) 11820-11826. doi:10.1021/jp503331e. 
[36] E. Padenko, L. van Rooyen, B. Wetzel, J. Karger-Kocsis, "Ultralow" sliding wear polytetrafluoro ethylene nanocomposites with functionalized graphene, J. Reinf. Plast. Compos. (2016) 731684416630817. doi:10.1177/0731684416630817.

[37] M. Han, J. Yun, H.-I. Kim, Y.-S. Lee, Effect of surface modification of graphene oxide on photochemical stability of poly(vinyl alcohol)/graphene oxide composites, J. Ind. Eng. Chem. 18 (2012) 752-756. doi:10.1016/j.jiec.2011.11.122.

[38] T.R. Bierschenk, T. Juhlke, H. Kawa, R.J. Lagow, Liquid phase fluorination, EP0441807 B1, 1995. http://www.google.com/patents/EP0441807B1 (accessed June 23, 2016).

[39] M. Acik, S. Yagneswaran, W. Peng, G. Lee, B.R. Lund, D.W. Smith Jr., Y.J. Chabal, Spectroscopic evaluation of out-of-plane surface vibration bands from surface functionalization of graphite oxide by fluorination, Carbon. 77 (2014) 577-591. doi:10.1016/j.carbon.2014.05.062.

[40] L. Cheng, S. Jandhyala, G. Mordi, A.T. Lucero, J. Huang, A. Azcatl, R. Addou, R.M. Wallace, L. Colombo, J. Kim, Partially Fluorinated Graphene: Structural and Electrical Characterization, ACS Appl. Mater. Interfaces. 8 (2016) 5002-5008. doi:10.1021/acsami.5b11701.

[41] E.P. Dillon, C.A. Crouse, A.R. Barron, Synthesis, Characterization, and Carbon Dioxide Adsorption of Covalently Attached Polyethyleneimine-Functionalized Single-Wall Carbon Nanotubes, ACS Nano. 2 (2008) 156-164. doi:10.1021/nn7002713.

[42] S.D. Kim, J.W. Kim, J.S. Im, Y.H. Kim, Y.S. Lee, A comparative study on properties of multi-walled carbon nanotubes (MWCNTs) modified with acids and oxyfluorination, J. Fluor. Chem. 128 (2007) 60-64. doi:10.1016/j.jfluchem.2006.10.010.

[43] J.T. Robinson, J.S. Burgess, C.E. Junkermeier, S.C. Badescu, T.L. Reinecke, F.K. Perkins, M.K. Zalalutdniov, J.W. Baldwin, J.C. Culbertson, P.E. Sheehan, E.S. Snow, Properties of Fluorinated Graphene Films, Nano Lett. 10 (2010) 3001-3005. doi:10.1021/nl101437p.

[44] A. Tressaud, E. Durand, C. Labrugère, A.P. Kharitonov, L.N. Kharitonova, Modification of surface properties of carbon-based and polymeric materials through fluorination routes: From fundamental research to industrial applications, J. Fluor. Chem. 128 (2007) 378-391. doi:10.1016/j.jfluchem.2006.12.015.

[45] Z. Wang, J. Wang, Z. Li, P. Gong, X. Liu, L. Zhang, J. Ren, H. Wang, S. Yang, Synthesis of fluorinated graphene with tunable degree of fluorination, Carbon. 50 (2012) 54035410. doi:10.1016/j.carbon.2012.07.026.

[46] S.-M. Yun, J.-W. Kim, M.-J. Jung, Y.-C. Nho, P.-H. Kang, Y.-S. Lee, An XPS Study of Oxyfluorinated Multiwalled Carbon Nano Tubes, Carbon Lett. 8 (2007) 292-298. doi:10.5714/CL.2007.8.4.292.

[47] F.-G. Zhao, G. Zhao, X.-H. Liu, C.-W. Ge, J.-T. Wang, B.-L. Li, Q.-G. Wang, W.-S. Li, Q.-Y. Chen, Fluorinated graphene: facile solution preparation and tailorable properties by fluorine-content tuning, J. Mater. Chem. A. 2 (2014) 8782-8789. doi:10.1039/C4TA00847B.

[48] I. Palchan, M. Crespin, H. Estrade-Szwarckopf, B. Rousseau, Graphite fluorides: An XPS study of a new type of C?F bonding, Chem. Phys. Lett. 157 (1989) 321-327. doi:10.1016/0009-2614(89)87255-0.

[49] V. Mazánek, O. Jankovský, J. Luxa, D. Sedmidubský, Z. Janoušek, F. Šembera, M. Mikulics, Z. Sofer, Tuning of fluorine content in graphene: towards large-scale 
production of stoichiometric fluorographene, Nanoscale. 7 (2015) 13646-13655. doi:10.1039/C5NR03243A.

[50] R. Zbořil, F. Karlický, A.B. Bourlinos, T.A. Steriotis, A.K. Stubos, V. Georgakilas, K. Šafářová, D. Jančík, C. Trapalis, M. Otyepka, Graphene Fluoride: A Stable Stoichiometric Graphene Derivative and its Chemical Conversion to Graphene, Small. 6 (2010) 2885-2891. doi:10.1002/smll.201001401.

[51] M. Bruna, B. Massessi, C. Cassiago, A. Battiato, E. Vittone, G. Speranza, S. Borini, Synthesis and properties of monolayer graphene oxyfluoride, J. Mater. Chem. 21 (2011) 18730-18737.

[52] V. Gupta, T. Nakajima, B. Žemva, Raman scattering study of highly fluorinated graphite, J. Fluor. Chem. 110 (2001) 145-151. doi:10.1016/S00221139(01)00422-5.

[53] G. Lalwani, W. Xing, B. Sitharaman, Enzymatic degradation of oxidized and reduced graphene nanoribbons by lignin peroxidase, J. Mater. Chem. B. 2 (2014) 63546362. doi:10.1039/C4TB00976B.

[54] G. Choudalakis, A.D. Gotsis, Permeability of polymer/clay nanocomposites: A review, Eur. Polym. J. 45 (2009) 967-984. doi:10.1016/j.eurpolymj.2009.01.027.

[55] L.E. Nielsen, Models for the Permeability of Filled Polymer Systems, J. Macromol. Sci. Part - Chem. 1 (1967) 929-942. doi:10.1080/10601326708053745.

[56] R.K. Bharadwaj, Modeling the Barrier Properties of Polymer-Layered Silicate Nanocomposites, Macromolecules. 34 (2001) 9189-9192. doi:10.1021/ma010780b.

[57] G.H. Fredrickson, J. Bicerano, Barrier properties of oriented disk composites, J. Chem. Phys. 110 (1999) 2181-2188. doi:doi:10.1063/1.477829.

[58] A.A. Gusev, H.R. Lusti, Rational Design of Nanocomposites for Barrier Applications, Adv. Mater. 13 (2001) 1641-1643. doi:10.1002/15214095(200111)13:21<1641::AID-ADMA1641>3.0.C0;2-P.

[59] R. Moriche, S.G. Prolongo, M. Sánchez, A. Jiménez-Suárez, M.J. Sayagués, A. Ureña, Morphological changes on graphene nanoplatelets induced during dispersion into an epoxy resin by different methods, Compos. Part B Eng. 72 (2015) 199-205. doi:10.1016/j.compositesb.2014.12.012.

[60] A. Greco, C.E. Corcione, A. Maffezzoli, Effect of multi-scale diffusion on the permeability behavior of intercalated nanocomposites, J. Membr. Sci. 505 (2016) 92-99. doi:10.1016/j.memsci.2016.01.029. 